\title{
ARTEFATOS DE COMUNICAÇÃO PARA AMBIENTE DE COMUNIDADES DE PRÁTICA BILÍNGUE
}

\section{COMMUNICATION ARTIFACTS FOR BILINGUAL COMMUNITIES OF PRACTICE ENVIRONMENT}

\author{
SAITO, Daniela Satomi (1) \\ PIVETTA, Elisa Maria (2) \\ ULBRICHT, Vania Ribas(3) \\ (1) UFSC-IFSC, mestre \\ e-mail:daniela.saito@gmail.com \\ (2) UFSC-UFSM, mestre \\ e-mail:elisa@cafw.ufsm.br \\ (3) UFSC, Doutora \\ e-mail:vrulbricht@gmail.com
}

\begin{abstract}
RESUMO
Os artefatos digitais de comunicação ampliam a possibilidade de aprendizagem e inclusão, em especial aos surdos. No entanto, os ambientes virtuais de ensino e aprendizagem carecem de artefatos adequados para ampliar a acessibilidade. Assim, o objetivo é apresentar parte do aprimoramento do ambiente Moodle para a formação de Comunidades de Prática (CoPs) e atender um público bilíngue (Libras/Português), respeitando as diferenças. As mudanças realizadas foram: suporte à formação de CoPs informais abertas e fechadas; integração de ferramenta de chat e tradutor automatizado; funcionalidades para upload e captura de vídeo; e estudos sobre ferramentas de videoconferência.
\end{abstract}

Palavras-chave: artefatos de comunicação, HTML5, comunidades de prática, surdos

\begin{abstract}
Digital communication artifacts extend inclusion and learning possibilities, specially to the deafs. However, learning management systems require appropriate artifacts to broaden accessibility. So, the objective is to present part of upgrading of Moodle to formation of Communities of Practice (CoPs) and attend a bilingual public (Libras/Portuguese), respecting the differences. Changes made were: support the formation of open and closed informal CoPs; integration of chat and automated translation tool; functionalities for upload and video capturing; and studies on videoconferencing tool.
\end{abstract}

Keywords: communication artifacts, HTML5, communities of practice, deaf 


\section{INTRODUÇÃO}

O avanço da tecnologia, em especial da Internet, muito tem contribuído para a inclusão do surdo, tanto nos meios sociais, culturais e de aprendizagem. Os artefatos tecnológicos de comunicação influenciam a vida de todos os cidadãos e fortalecem a possibilidade de inclusão. No entanto, no que se refere aos ambientes digitais acessíveis, os passos são lentos. O censo brasileiro (IBGE, 2010), registrou 9.722.163 pessoas com deficiência auditiva, entre as quais, 344.200 são consideradas surdas. Mesmo sendo um número alto, do ponto de vista econômico, este não é visto como um mercado ascendente, o que resulta em poucos ou raros investimentos no desenvolvimento e ambientes virtuais acessíveis a surdos.

Para além das dificuldades, os ambientes disponíveis para aprendizagem nas instituições de ensino são, na grande maioria, ambientes sem custo, construídos na filosofia do software livre, como é o caso do Moodle (Modular Object-Oriented Dynamic Learning Environment). Ambientes desenvolvidos neste modelo são todos bem-vindos, porém por ora carecem de acessibilidade, como revelam as pesquisas de (FAJARDO;VIGO; SALMERÓN, 2009; PIVETTA et al., 2013).

Neste contexto, o objetivo deste trabalho é apresentar parte do processo de aprimoramento do ambiente virtual de ensino aprendizagem Moodle, no que respeita a disponibilização de um ambiente para formação de Comunidades de Prática (CoPs). Além disso, as modificações foram realizadas na perspectiva de atender um público bilíngue (Libras/Português), respeitando as diferenças entre as modalidades de comunicação para a interação entre seus membros.

Este artigo está dividido em oito seções. A seção dois descreve sobre acessibilidade Web, a três discorre sobre Comunidades de Prática. A seção quatro, expõem-se o grupo de pesquisa do projeto WebGD, onde está inserido esta investigação e alguns trabalhos relacionados a este estudo. A seção cinco apresenta a metodologia e a seis as discussões e os resultados. Por fim, são apresentadas as considerações finais acerca do trabalho desenvolvido e as referências utilizadas.

\section{ACESSIBILIDADE WEB}

O cerne da acessibilidade web está na universalidade, ou seja, na possibilidade de qualquer usuário, que utilize um agente, seja software ou hardware, de perceber, entender, navegar e interagir com o conteúdo de um site (THATCHER et al., 2002). A acessibilidade dos recursos web é uma premissa fundamental para a inclusão na atual sociedade. No entanto, um estudo realizado em 2012 pelo $\mathrm{W} 3 \mathrm{C} . \mathrm{br} / \mathrm{NIC} . \mathrm{br}$ indica que somente $2 \%$ das páginas web governamentais são acessíveis (W3CGT, 2012). Neste propósito, é fundamental se referir à Web Accessibility Initiative (WAI) do World Wide Web Consortium (W3C).-A Web Accessibility Initiative (WAI) é uma iniciativa que tem como proposta apresentar diretrizes e recomendações para prover acesso e oportunidades igualitárias às pessoas, considerando os diversos tipos de habilidades. As proposições da WAI são consideradas referências quando discussões sobre acessibilidade Web são levantadas (WAI, 2012). Visando auxiliar aos desenvolvedores e autores de conteúdo na produção de material acessível às pessoas, a WAl articulou a elaboração da Web Content Accessibility Guidelines (WCAG), que hoje se encontra na versão 2.0 . 
O documento é organizado em termos de diretrizes e critérios de sucesso, sendo este último a referência para a definição do nível de conformidade de um web site em relação à acessibilidade. Segundo o WCAG 2.0 (2006), as diretrizes e critérios de sucesso de acessibilidade foram construídos com base em quatro princípios básicos: perceptível, operável, compreensível e robusto. Porém, em relação ao WCAG, Kelly et al (2007) apontam que embora o documento seja impecável em sua forma, é demasiadamente genérico, funcionando bem apenas para contextos mais simples. De acordo com os pesquisadores, em contextos que exigem análise e interpretação, as diretrizes deixam a desejar.

\section{COMUNIDADES DE PRÁTICA}

Comunidades de prática (CoP) é um termo cunhado originalmente por Wenger (1998), que define como sendo um grupo de pessoas que compartilham interesses comuns. Lave e Wenger (1991), definem CoPs como organizações informais que são naturalmente formadas entre praticantes de dentro e além das fronteiras de organizações formais.

Em termos estruturais, Wenger (1998) considera que uma comunidade de prática possui três elementos fundamentais:

- domínio: foco de interesse;

- comunidade: grupo de pessoas envolvidas nas interações e construção de relacionamentos em torno do domínio;

- prática: as pessoas aprendem juntas como fazer coisas pelas quais se interessam.

Fundamentado nestes conceitos e com a difusão das tecnologias, a possibilidade de aprendizado via internet proporcionou uma nova concepção, a de comunidades de prática virtuais. Uma Comunidade de Prática (CoP) virtual se estabelece dentro do mundo da informação e comunicação, em um espaço que não exige a presença física para que as relações se estabeleçam. Este espaço tem essência de real, pois os membros da comunidade interagem e constroem significados legítimos nas atividades que são realizadas.

As comunidades virtuais cresceram muito com a Internet e com as tecnologias da web porém não estão restritas a ela. Por este estudo envolver Ambientes Virtuais de Ensino e Aprendizagem (AVEAs), a internet é considerada base de apoio para o seu desenvolvimento. Saito e Ulbricht (2012), ao avaliar plataformas para AVEA, apontam o Moodle como um software que suporta uma proposta bilíngue (língua de sinais/língua oral). Em relação a ambientes bilíngues, investigadores do Institute for Language and Communication de Aachen, em conjunto com o Fraunhofer Institute for Applied Information Technology de Sankt Augustin, na Alemanha, que trabalham com Ambientes Virtuais de Ensino Aprendizagem (AVEAs), sugerem que um ambiente bilíngue torna mais fácil a comunicação e a compreensão dos conteúdos e aumenta a motivação, permitindo uma aprendizagem independente (STRAETZ, 2004).

Apesar da grande difusão e utilização de AVEAs, as atuais propostas desenvolvidas em Learning Managment Systems (LMSs), entre eles o Moodle, estão fortemente alicerçadas na lógica da língua escrita e falada e exploram de forma muito frágil os aspectos da visualidade, tão importante para o surdo (FAJARDO; VIGO; SALMERÓN, 2009; PIVETTA et al., 2013, FLOR; BLEICHER; VANZIN, 2014). Assim, este projeto apresenta uma proposta que vai ao encontro desta demanda por meio de uma plataforma que tem seu funcionamento balizado pelo 
arcabouço teórico proposto por Lave e Wenger (1991) e munido de ferramentas que possibilitam a modalidade de comunicação visuoespacial.

\section{PROJETO WEBGD E TRABALHOS RELACIONADOS}

A Universidade Federal de Santa Catarina (UFSC) foi precursora e inovadora ao criar o primeiro curso Letras-Libras com a finalidade de atender a especificidade dos surdos, nas modalidades a distância e presencial. Convergente com a iniciativa e com o objetivo de aprimorar a acessibilidade no Moodle, a equipe do projeto "WebGD - Ambiente Web Acessível com Objetos de Aprendizagem para Representação Gráfica"1 ${ }^{1}$, vem desenvolvendo pesquisas relacionadas à acessibilidade nos ambientes virtuais a surdos, ouvintes, cegos e videntes, utilizando Objetos de Aprendizagem e AVEAs acessíveis. Todavia, este artigo aborda mais especificamente o público surdo e as modificações necessárias para a implementação de um ambiente de Comunidades de Prática (CoP) virtuais desenvolvido em um AVEA (Moodle).

Em uma busca na literatura, verificou-se que são escassos os trabalhos que contemplam o tema CoP virtuais de aprendizagem acessíveis aos surdos. Em relação à integração de surdos e ouvintes, Trindade (2013), apresenta um framework conceitual para o design de ambientes colaborativos inclusivos para surdos e não-surdos. A autora aponta para a necessidade de desenvolvimento de ferramentas de comunicação que estejam em conformidade com a modalidade de comunicação dos surdos, entre outros artefatos tais como tradutores e glossários. No que diz respeito às CoPs, Ellaway, Dewhurst e McLeod (2004) aplicam a teoria de Wenger para constituir uma comunidade com estrutura formal (disciplinar) no intuito de criar um instrumento de validação de CoPs desenvolvidas em AVEAs. De acordo com os autores, a eficácia do AVEA como suporte, depende de como ele está sendo utilizado para facilitar a mediação das necessidades da comunidade, assim como das affordances ${ }^{2}$ das tecnologias disponíveis, sendo estes elementos fundamentais para a manutenção e cultivo das CoPs.

\section{METODOLOGIA}

Esta seção descreve a metodologia utilizada para implementar o suporte a comunidades virtuais informais para surdos e ouvintes no ambiente Moodle.

1. Adequar o ambiente Moodle para dar suporte a Comunidades de Prática de acordo com o que preconizam Lave e Wenger (1991).

2. Seleção e aprimoramento de ferramentas de comunicação

a. Chat

b. Videoconferência

3. Desenvolver/aprimorar meio de compartilhamento de conteúdos em vídeo

a. Captura e compartilhamento de vídeo

4. Acessibilidade de conteúdos

a. Produção de conteúdo em vídeo

b. Integrar os vídeos ao ambiente

\footnotetext{
${ }^{1}$ http://www.webgd.ufsc.br

${ }^{2}$ Atributo de um objeto que permite as pessoas saber como utilizá-lo, sendo que nas interfaces digitais, elas estão vinculadas a convenções apreendidas (PREECE; ROGERS, SHARP, 2005)
} 
c. Integração de software de tradução automática

\section{DISCUSSÕES E RESULTADOS}

Para atingir o objetivo proposto neste artigo está sendo realizado o aprimoramento do ambiente virtual de ensino aprendizagem Moodle, em consonância com a teoria de Lave e Wenger (1991) no que respeita à formação de Comunidades de Prática (CoPs) e atendendo a requisitos de acessibilidade ao público surdo e ouvinte.

Uma das características fundamentais das Comunidades de Prática (CoP) é a possibilidade do ambiente virtual dar suporte a criação de comunidades informais. Portanto, partiu-se da premissa de que a informalidade das comunidades deveria estar presente no Moodle. Porém, em sua estrutura padrão, o Moodle suporta apenas a formação de comunidades formais. Desta forma, foram implementadas mudanças para possibilitar a criação de CoPs informais, adicionando a possibilidade de qualquer membro (professor, aluno, administrador) criar uma comunidade. Além disso, duas modalidades de CoPs foram implementadas no ambiente: as comunidades abertas, na qual qualquer pessoa consegue participar sem restrições para ingresso na comunidade; e a outra modalidade, que são as comunidades moderadas ou fechadas, que possuem a capacidade de limitar o aceite ou não de novos membros à comunidade. A Figura 1 ilustra como será o ambiente das Comunidades.

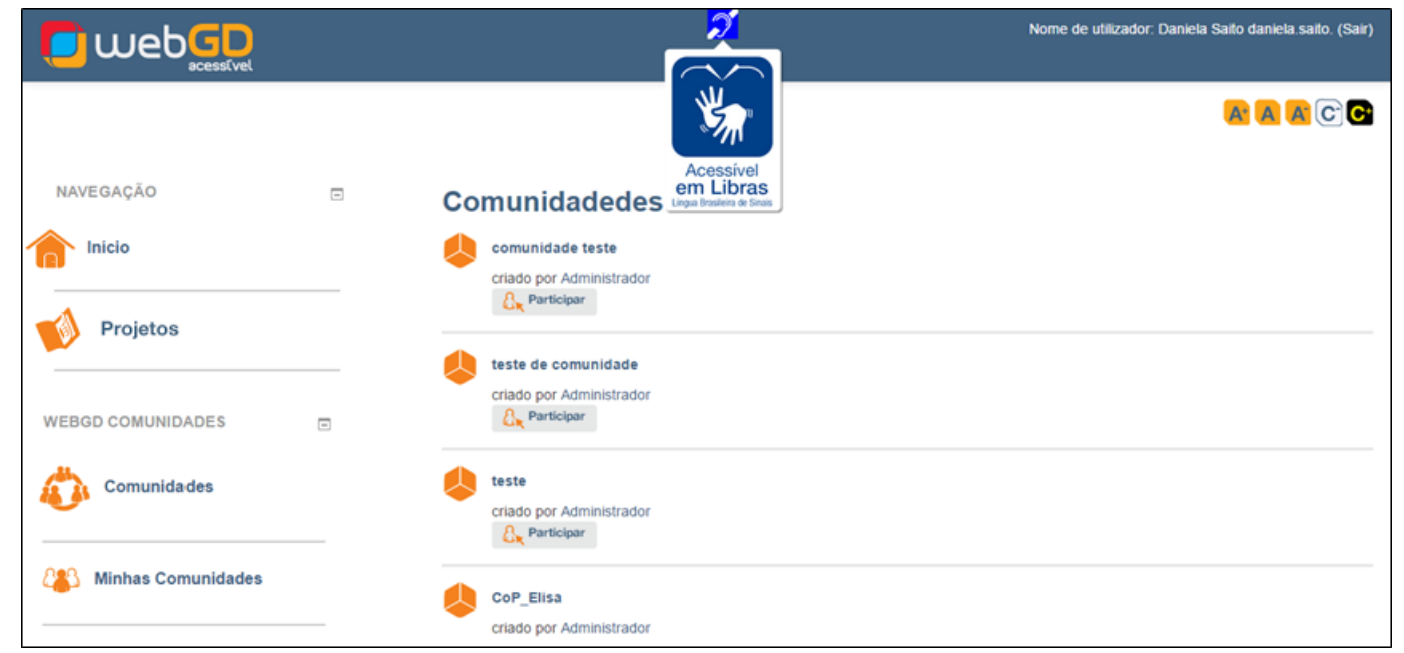

Figura 1 - Ambiente Comunidades de Prática no Moodle

Fundamentado na plataforma escolhida (Moodle 2.6.1) para o aprimoramento do ambiente, foram pesquisadas as ferramentas de comunicação que a versão suporta. De acordo com Schnneider (2012), as ferramentas podem ser síncronas (chat, chat com vídeo, videoconferência) ou assíncronas (e-mail, fórum, wikis, blogs). Embora nos estudos de Schneider (2012), o chat tenha apresentado menor aceitação entre os surdos por exigir maior velocidade de leitura, e seu uso seja dificultado pela baixa proficiência com o português, a ferramenta foi selecionada e testada acreditando que o chat representa um canal de comunicação entre surdos e ouvintes. Todavia, salienta-se que a ferramenta chat para aceite 
de qualquer público deve oferecer uma interface "amigável", com características baseadas na ergonomia de software (LABUTIL, 2011).

Foi verificado que o Moodle não tem uma ferramenta adequada para conversas instantâneas entre os usuários. O ambiente tem um chat próprio, mas essas conversas são definidas por meio de agendamento de datas pela plataforma. Outro ponto negativo é a falta de privacidade, pois o mecanismo do chat não contém uma estrutura privada de conversa entre os usuários. Desta forma, todos os usuários podem acessar todas as conversas.-Assim, foram testadas algumas ferramentas de comunicação via chat, gratuitas, sendo que todo o procedimento está descrito em Pivetta et al. (2014b) .

Entre as ferramentas testadas o Gmail $_{\text {chat }}{ }^{3}$ permite fazer conversas privadas com usuários "logados" e "deslogados", mas não permite realizar conversas em grupos. Trabalha com a metodologia AJAX (Asynchronous JavaScript and XML) sem a necessidade de carregar toda a página, mas sim "pequenos pedaços" dela. Em virtude destas características este chat foi o selecionado para integrar a plataforma Moodle e ser alterado de modo a dar suporte à funcionalidade de conversas em grupos. A opção de chat estará presente em todo o ambiente, sendo que detalhes de seu desenvolvimento estão descritos em Pivetta et al (2014b) e um exemplo pode ser visualizado na Figura 2.

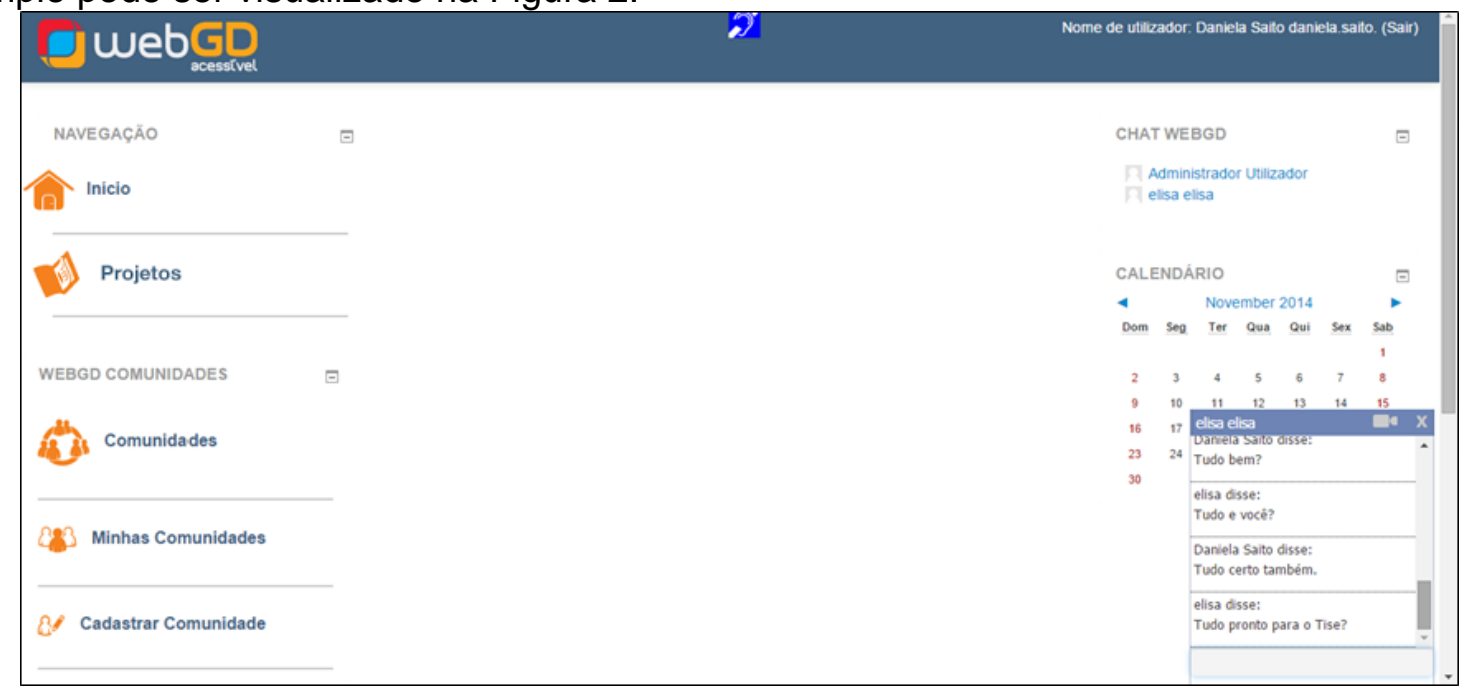

Figura 2 - Chat integrado ao ambiente.

Em relação ao compartilhamento de informações foi optado também pelo uso de vídeos. Esta opção foi identificada como alternativa para a videoconferência, visto que situações de videoconferência necessitam da presença de dois ou mais integrantes e de servidor dedicado para streaming ${ }^{4}$. Assim, duas estratégias foram definidas para o registro dos conteúdos: upload vídeo e captura de vídeo via plataforma utilizando a webcam. A Figura3 mostra a ativação da webcam.

\footnotetext{
${ }^{3}$ Apesar do nome, não tem ligação com o Google. http://itswadesh.wordpress.com/2011/05/07/gmail-facebook-stylejquery-chat/

${ }_{4}$ computador configurado para processar dados, permitir acesso a arquivos e ou permitir execução de softwares remotamente, ligado 24 horas por dia em um link de internet de alta velocidade.
} 


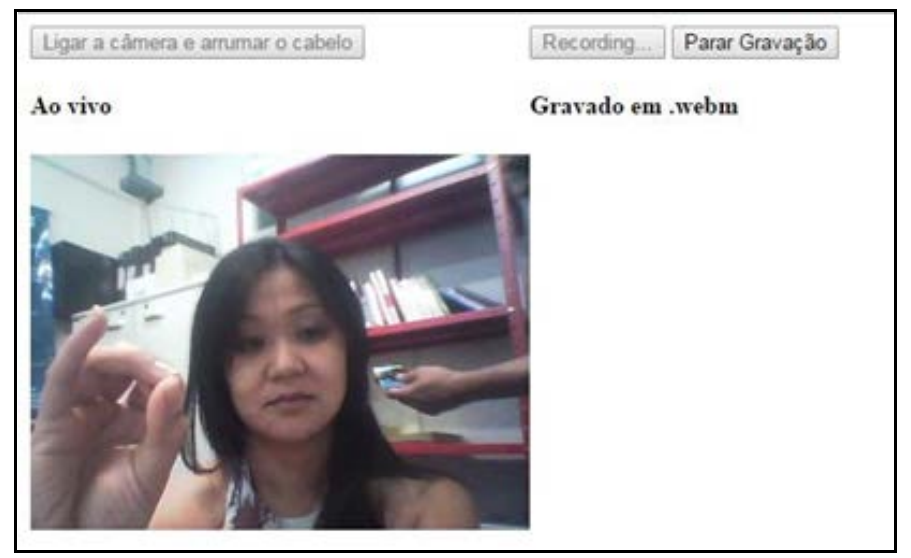

Figura 3 - Visualização do protótipo com a webcam ativa

$\mathrm{Na}$ web, esse recurso normalmente é desenvolvido usando a tecnologia Flash ou novas tecnologias, como o HTML5 (Hypertext Markup Language, version 5). Optou-se pelo desenvolvimento em HTML5 pelos seguintes motivos: (1) redução da adesão no uso de aplicações em Flash em diversos dispositivos; (2) a tecnologia Flash possui objeções no que se refere ao suporte ao desenvolvimento de sites acessíveis; (3) a previsão é que a tecnologia HTML $5^{5}$ passe a ser adotada como padrão para o desenvolvimento web para os próximos anos, sendo que parte dos browsers atuais já dá suporte à tecnologia.

Assim, a solução para a gravação de vídeo foi desenvolvida para que o usuário, utilizando a sua webcam, possa gravar o seu vídeo (Figura 1), postá-lo na comunidade ou realizar o download do arquivo. O formato selecionado para a gravação da mídia foi o WebM, que é um formato aberto de arquivos de vídeo, livre de royalty, para a web (WEBM, 2014). Os arquivos em WebM consistem de streams de vídeo codificados em VP8 ${ }^{6}$ (BANKOSKI et al., 2011), em conjunto com streams de áudio codificados em Vorbis $^{7}$ (VORBIS, 2003) e armazenados em uma estrutura de container de mídia baseada no formato Matroska ${ }^{8}$.

Assim sendo, para a gravação dos vídeos compactados no formato Webm, foi utilizada uma biblioteca de JavaScript chamada Whammy ${ }^{9}$ em conjunto com uma nova funcionalidade do HTML5, que ainda está em fase de draft ${ }^{10}$ pelo W3C, chamada getUserMedia (BURNETT et al., 2014). A gravação de vídeo funciona totalmente na máquina do usuário, sendo que o

\footnotetext{
${ }^{5}$ De acordo com o W3C, o HTML5 permite a manipulação dos elementos HTML, possibilitando ao desenvolvedor modificar as características dos objetos de forma não intrusiva e transparente ao usuário. Além disso, cria novas tags, modifica a função de outras e modifica a forma de codificação e organização das páginas, tornando-as mais semânticas, com menos código (FERREIRA; EIS, 2014).

${ }^{6}$ O VP8 é uma tecnologia de propriedade da empresa Google que reduz a taxa de dados explorando a coerência temporal e espacial dos sinais de vídeo e a tolerância do sistema visual humano (BANKOSKI et al., 2011).

${ }^{7} \mathrm{O}$ codec Vorbis, é um formato totalmente livre, aberto e sem patentes. Realiza a compactação de áudio com perda de qualidade para reduzir o espaço necessário para o armazenamento dos arquivos (VORBIS, 2003).

${ }^{8}$ Container Multimídia de padrão aberto, extensível, de código aberto.

${ }^{9}$ https://github.com/antimatter15/whammy

${ }^{10}$ Processo anterior à homologação de um padrão oficial
} 
arquivo gerado (Figura 4) e velocidade de compressão do vídeo dependem apenas do computador utilizado.

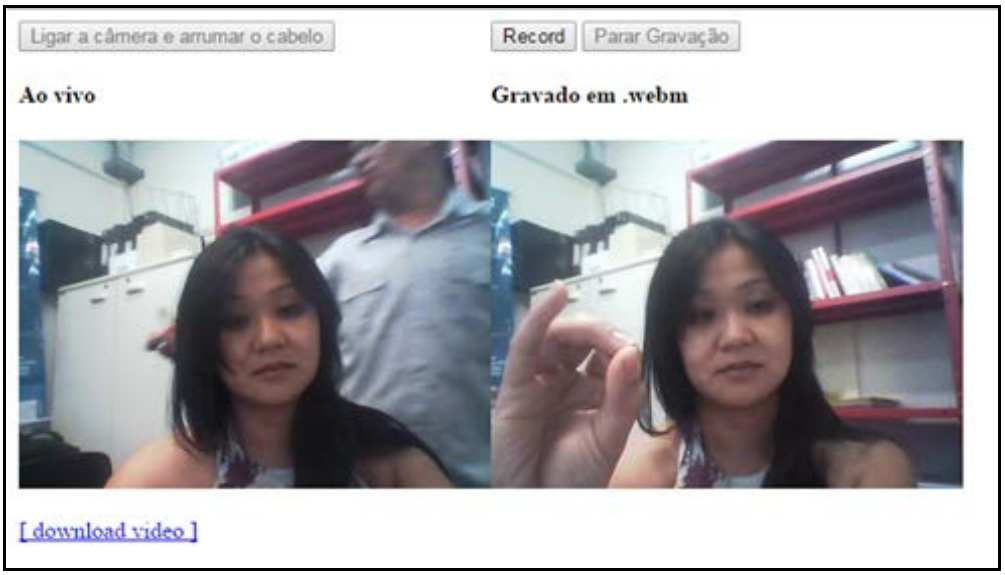

Figura 4 - Visualização do protótipo com a reprodução do vídeo gravado

Para realizar a gravação do vídeo, foi criada uma função em JavaScript chamada turnOnCamera. A função é vinculada ao botão Gravar, vinculado ao id "record-me". Quando o usuário ativa a gravação com um clique sobre o botão, o estado da gravação passa para true (verdadeiro), liberando a ativação da webcam na gravação. A função finishVideoSetup, configura o vídeo atribuindo valores propriedades de altura (width) e largura (height) do arquivo.

Para atender a questão da videoconferência, como a versão original do Moodle não apresentou compatibilidade com os plugins disponíveis dessa categoria e as ferramentas de chat não apresentavam suporte a vídeo. Assim, foi realizada uma busca-na perspectiva de identificar um software que pudesse ser integrado ao sistema. No entanto, as soluções encontradas não permitiram a integração com o Moodle; além disso, algumas ferramentas identificadas são proprietárias, enquanto opções sem custos limitam a disposição de canais para realizar as videoconferências. Uma opção seria utilizar o software Hangouts, um aplicativo desenvolvido pela Google, que atende às expectativas, todavia possui o inconveniente de vincular o login na plataforma Google e não ser open source. Além de que, qualquer atividade realizada no Hangouts não ficará registrada para posterior avaliação dos professores e/ou pesquisadores. Outra solução é continuar pesquisando um software de videoconferência que ofereça o suporte necessário e as qualidades especificadas em Trindade (2013).

Para explicar o conteúdo do site, foram desenvolvidos vídeos em Libras, os quais seguiram as etapas necessárias para a produção e edição. Além de todo o preparo, para disponibilizar os vídeos está em desenvolvimento um plugin para agregar os vídeos à plataforma Moodle. Nesta etapa, o desafio foi criar vídeos com canal alfa ${ }^{11}$. Em busca por soluções mais acessíveis, optou-se por desenvolver uma funcionalidade para visualização de vídeos transparentes utilizando as tecnologias HTML5 e JavaScript com o uso do framework JQuery. A seguir são descritas as etapas de produção e desenvolvimento:

${ }^{11}$ O canal alfa define a opacidade de um pixel numa imagem. 
- captura dos vídeos utilizando o canal alfa;

- para cada vídeo foram exportados dois novos vídeos, um apenas com o canal alfa, e outro com os canais RGB;

- criação de uma nova composição com o dobro da altura do vídeo original, com os vídeos e dispostos um acima do outro, estado acima, o vídeo o com canais RGB e abaixo o que possui apenas o canal alfa;

- vídeo (com o dobro da altura) embarcado no navegador utilizando a "tag" vídeo padrão do HTML5, porém invisível ao usuário e criação de dois "canvas" (elemento gráfico do HTML5): um para leitura do vídeo e outro para saída ao usuário;

- No primeiro "canvas" é feita a leitura ponto-a-ponto do vídeo por JavaScript e no segundo são exibidos apenas os pontos que existiam na camada inferior do vídeo, ou seja, apenas aqueles pontos que não eram transparentes.

Desse modo obteve-se um resultado satisfatório, tanto em termos de desempenho quanto em qualidade para visualização. O resultado é visto pelo usuário, quando acionado o ícone

(mão azul), exibe o vídeo em uma janela flutuante e móvel o conteúdo em língua de sinais, como pode ser visualizado na Figura 5.

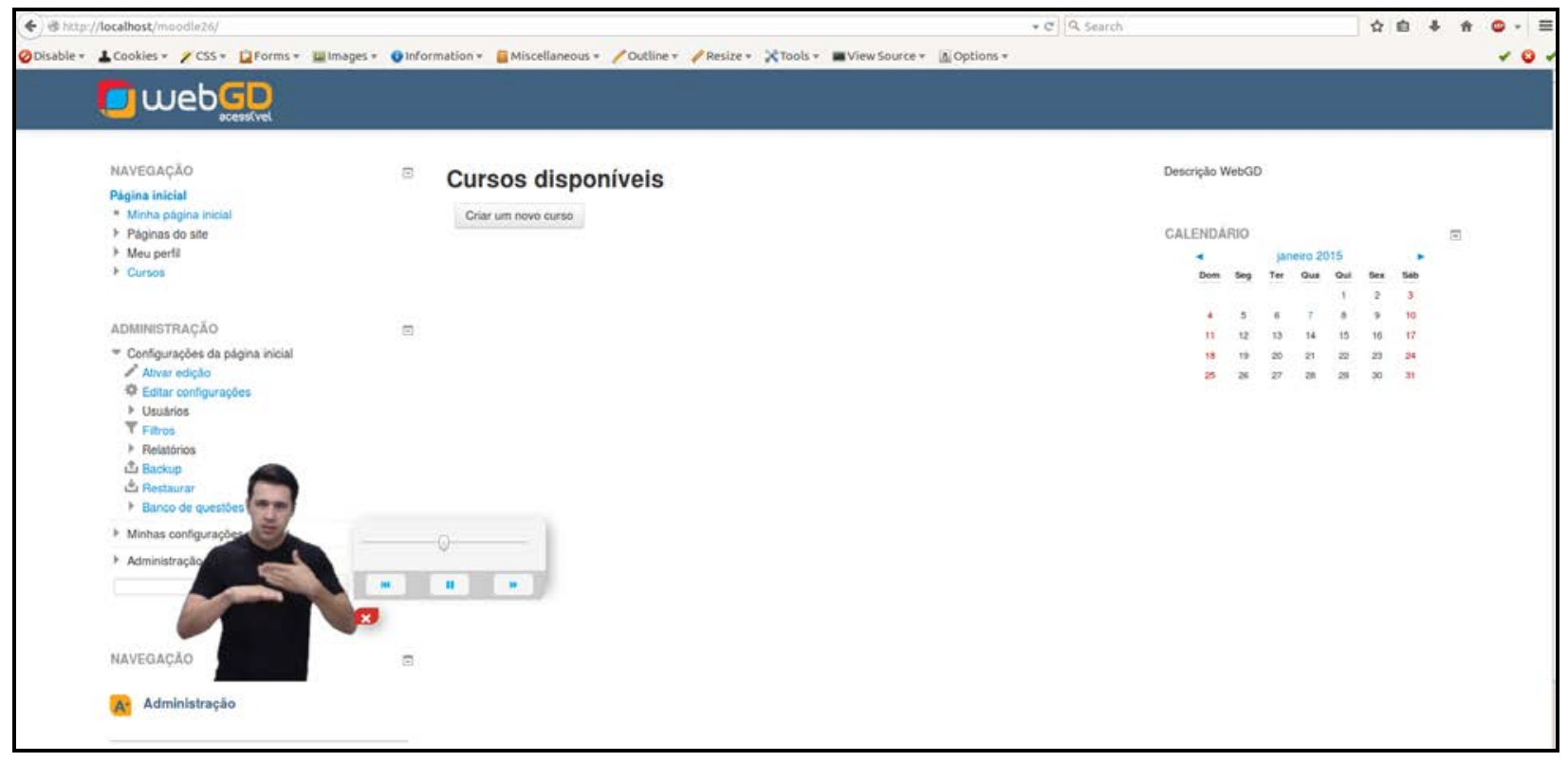

Figura 5 - Exibição de vídeo transparente em janela flutuante

Em relação aos softwares de tradução, um levantamento preliminar via questionário online ${ }^{12}$ buscou verificar a opinião acerca de softwares como o Rybená, ProDeaf e HandTalk. Entre os participantes da pesquisa, 44 responderam que já utilizaram ou testaram um tradutor automatizado. A maioria dos que já utilizaram um tradutor automatizado referenciam o

${ }^{12}$ Os dados de análise desta pesquisa ainda não foram publicados. 
ProDeaf ${ }^{13}$, alguns também citaram Rybená ${ }^{14}$ Entretanto comentam sobre as limitações destes softwares, como por exemplo nas respostas a seguir:

"Já testei o ProDeaf, achei bem legal mas parece que o vocabulário é limitado".

"Sim, Prodeaf. É escasso nos sinais".

"Sim, não por necessidade, mas por curiosidade. ProDeaf, achei funcional."

"Rybená é muito bom e ProDeaf ainda é muito mecânico e robotizado demais, não transparecendo nenhuma naturalidade, fato que não acontece tanto com o Rybená".

“... trazem uma proposta interessante, mas não mostram bem o sinal, são um pouco duros e muito rápido".

As respostas relatam que estes softwares ainda não são funcionais. Porém, são alternativas para auxiliar na tradução. Devido ao ProDeaf ser o mais citado foi o selecionado para ser integrado ao ambiente proposto e pode ser visualizado na parte superior e central da Figura 2, representado pelo ícone 3 e quando ativo na Figura 1.

\section{CONSIDERAÇÕES FINAIS}

Até o presente momento, o Moodle está sendo adequado para atender um público bilíngue e as ferramentas elencadas estão sendo integradas ao ambiente. No que respeita o suporte às CoPs, as mudanças implementadas foram em relação à criação de CoPs informais, visto que em sua estrutura padrão, o Moodle suporta apenas a formação de comunidades formais (disciplinares).

Em relação às ferramentas de comunicação, verificou-se que alguns plugins disponíveis não apresentaram compatibilidade com a versão de plataforma selecionada, o que implicou na busca por ferramentas open source para integrar ao ambiente, bem como no desenvolvimento de novas ferramentas na inexistência de soluções compatíveis para ferramentas de chat e de videoconferência.

Em relação ao chat, vale salientar que, embora exista um módulo de chat disponível no Moodle, este não atende às necessidades de uma CoP. Visando ofertar uma solução adequada às CoPs, fez-se necessária a busca por uma ferramenta de conversação que estivesse a disposição dos usuários a qualquer horário. Assim, foi selecionada a ferramenta mais compatível com o Moodle para que as devidas alterações de código fossem realizadas.

Para atender a questão da videoconferência, como a versão original do Moodle não apresentou compatibilidade com os plugins disponíveis dessa categoria foi realizado uma busca na perspectiva de encontrar uma que pudesse ser integrada no sistema. No entanto, as soluções encontradas não permitiram a integração no Moodle. Além de serem ferramentas proprietárias, a opção sem custos limita a disposição de canais para realizar as videoconferências, demandando um aprofundamento das pesquisas relativas a esta modalidade de comunicação e que ofereça o suporte necessário e as qualidades especificadas em Trindade (2013).

\footnotetext{
13 http://prodeaf.net/ - as versões celular e básica para web são gratuitas

14 http://www.rybena.com.br/site-rybena/
} 
No que respeita a vídeos, mesmo que pesquisas apontam a necessidade de associar a outros tipos de mídia, eles são de grande importância em ambientes bilíngue (surdos e ouvintes), assim buscou-se desenvolver uma ferramenta que pudesse auxiliar na comunicação dos surdos, visto que a linguagem por eles utilizada é visuoespacial. Assim, buscou-se respeitar as características de comunicação do surdo para propiciar outros meios de comunicação e compartilhamento de vídeos.

Em relação ao compartilhamento de vídeos, nota-se que o modelo predominante de compartilhamento de vídeos gerados pelo usuário é uma tarefa onerosa, exigindo a utilização de um conjunto de aplicações até chegar à postagem do conteúdo em um ambiente digital. Considerando a importância da usabilidade para estimular o usuário a compartilhar conteúdos, a opção de captura de vídeo e sua posterior inserção utilizando apenas funcionalidades do ambiente parece ser uma solução plausível. Todavia, é necessário realizar uma investigação empírica para testar a ferramenta desenvolvida. Este será um dos próximos passos da pesquisa, onde o ambiente Moodle otimizado será utilizado para atender a implantação e cultivo de comunidades de prática com a finalidade de testar as ferramentas ali integradas. As Comunidades de Prática criadas e cultivadas deverão ter como usuários iniciais os voluntários cadastrados em outras etapas do projeto não abordadas neste artigo. Estes deverão ser os responsáveis por "convidar" e divulgar o ambiente a outros potenciais usuários.

\section{REFERÊNCIAS BIBLIOGRÁFICAS}

BANKOSKI, J. et al. VP8 Data Format and Decoding Guide. November, 2011. Disponível em: <http://tools.ietf.org/html/rfc6386>. Acesso em outubro de 2014.

BURNET, D. C.; BERGKVIST, D.; JENNINGS, C.; NARAYANAN, A. Media Capture and Streams. W3C Editors Draft 05 December 2014. Disponível em <http://w3c.github.io/mediacapture-main/>, Acesso em dezembro de 2014.

ELLAWAY R.; DEWHURST, D.; MCLEOD, H. Evaluating a virtual learning environment in the context of its community of practice. ALT-J, Research in Learning Technology. v. 12, n. 2, Jun., 2004, p. 125-145.

FAJARDO, I.; VIGO, M.; SALMERÓN, L. Technology for supporting web informaiton search and learning in Sign Language. Interacting with Computers. v. 21, n. 4, p. 243-256, ago 2009.

FERREIRA, E.; EIS, D. HTML5 - Curso W3C Escritório Brasil. Disponível em: <http://www.w3c.br/pub/Cursos/CursoHTML5/html5-web.pdf>. Acesso em novembro de 2014.

IBGE. Censo Demográfico 2010: Características Gerais da População, Religião e Pessoas com Deficiência. Rio de Janeiro: Ministério do Planejamento, Orçamento e Gestão, 2012. 215p.

KELLY, B. et al. Accessibility 2.0: People, Policies and Processes. In: Proceedings of the 2007. International Cross-disciplinary Conference on Web Accessibility, W4A. Proceedings... New York, USA: ACM Press, p. 138-147.

LABUTIL. Ergolist. 2011. Disponível em: <http://www.labutil.inf.ufsc.br/>. Acesso em agosto de 2014.

LAVE, J.; WENGER, E. Situated Learning. New York: Cambridge University Press. 1991. 
PIVETTA, E. M.; SAITO, D. S.; ALMEIDA, A. M. P.;ULBRICHT, V. R. Contribuições para o design de interface de um Ambiente Virtual de Ensino Aprendizagem acessível a surdos. InfoDesign - Revista Brasileira de Design da Informação, v. 10, n. 2, p. 193-206. 2013.

PIVETTA, E. M. et al. Otimização do Moodle para dar suporte a Comunidades de Prática acessíveis a surdos e ouvintes. In: XIX Conferência Internacional sobre Informática na Educação. Anais eletrônico.... Fortaleza, 2014b.

PREECE, J; ROGERS, Y.; SHARP, H. Design de interação: além da interação homem-computador. Porto Alegre: Bookman. 548p. 2005.

SCHNEIDER, E. I. Uma contribuição aos ambientes virtuais de aprendizagem (AVAs) suportados pela teoria da cognição situada (TCS) para pessoas com deficiência auditiva. Dissertação (Mestrado em Engenharia e Gestão do Conhecimento). Programa de Pós-Graduação em Engenharia e Gestão do Conhecimento da Universidade Federal de Santa Catarina. Florianópolis: Universidade Federal de Santa Catarina. 2012.

STRAETZ, Katja et al. An e-Learning Environment for Deaf Adults. In: 8th ERCIM Workshop. User Interfaces for All 2004. Proceedings... Viena, Austria, 2004.

THATCHER, J. et al. Constructing Accessible Web Sites. [S.I.]: Glasshaus, 2002.

TRINDADE, D. F. G. InCoP: um framework conceitual para o design de ambientes colaborativos inclusivos para surdos e não surdos de cultivo de comunidades de prática. Tese (Doutorado em Informática) - Programa de Pós-Graduação em Informática do Setor de Ciências Exatas da Universidade Federal do Paraná. 168f. Curitiba, 2013.

VORBIS. Vorbis.com. 2011. Disponível em: <http://www,vorbis.com/>. Acesso em outubro de 2014.

WAI. Web Accessibility Initiative. Disponível em: <http://www.w3.org/WAI/>, acesso em novembro de 2012.

WCAG20. Web Content Accessibility Guidelines 2.0. W3C Accessibility Initiative. Disponível em: <http://www.w3.org/TR/WCAG20/>. 2006. Acesso em novembro 2012.

W3CGT. GT Acessibilidade. Disponível em: <http://www.w3c.br/GT/GrupoAcessibilidade\#w3c_inicio_conteudo>. Acesso dezembro de 2012.

WEBM. WebM: an open web media project. 2014. Disponível em: < http://www.webmproject.org/>. Acesso em outubro de 2014.

WENGER, E. Communities of Practice: learning, meaning and identity. New York: Cambridge University Press. 1998. 